\title{
Basadre entre el Sesquicentenario y el Bicentenario de la independencia del Perú. A propósito de la reedición de El azar en la historia y sus límites ${ }^{1}$
}

Después de 48 años, Taurus reedita el clásico libro de Jorge Basadre El azar en la historia y sus límites (2021) ¿Por qué reeditar este libro en particular dentro de la vasta obra de Basadre? Además de que la primera edición estaba agotada hace décadas, la actual coyuntura del bicentenario de la independencia del Perú parece la razón más atendible dado el tema de este libro. Tras casi medio siglo de producción historiográfica sobre la independencia, no obstante, mucho (nuevo o repetido) se ha dicho y los debates, al parecer, han cambiado. En tal sentido, en esta edición hubiera sido importante añadir un prólogo que explique el contexto de publicación de este libro, además de su vigencia e importancia. Las siguientes líneas son un intento de cubrir ese vacío.

El azar en la historia... no es una síntesis narrativa sobre la independencia peruana, es un texto que se inscribe dentro un debate que busca explicar, de forma general, la causa de la independencia y porqué se dio de forma tardía y con apoyo externo. Cuando se publicó en 1973, el Perú se encontraba en la coyuntura conmemorativa del Sesquicentenario de la independencia del Perú que, como es de esperar, sacó a relucir un fuerte discurso nacionalista que resaltaba la participación de todos los peruanos en la lucha por su libertad, desde las elites hasta los indígenas. En 1972, sin embargo, se publicó la compilación La independencia en el Perú (IEP), donde en un ensayo escrito por Heraclio Bonilla y Karen Spalding (1972), se afirmaba, en contraposición al discurso oficial de la conmemoración, que la independencia peruana había sido concedida por los ejércitos extranjeros. Ello debido a que las elites peruanas no querían la independencia por temor a perder sus privilegios y al desborde popular, en especial de los indígenas. De otra parte, las clases populares no mostraron interés en la lucha dado que la independencia no les beneficiaba socialmente. Teniendo en cuenta estas premisas, la ruptura con España no significó para el Perú, a diferencia de las revoluciones burguesas en Francia y EEUU, un real cambio social y económico. No fue una "revolución", apenas un cambio de dirigentes.

En su momento, el mencionado ensayo causó mucho revuelo y rechazo de parte de los historiadores miembros de la Comisión Nacional del Sesquicentenario de la Independencia del Perú (CNSIP) quienes sugirieron incluso su censura. El gobierno de Juan Velasco Alvarado, sin embargo, no escuchó esos reclamos y pareció más bien apoyar esas nuevas ideas, al menos en parte de la prensa de gobierno. Dada la popularidad del ensayo ${ }^{2}$, los miembros de la CNSIP trasladaron sus críticas a la prensa donde se descalificó el ensayo por antinacionalista e incluso se le acusó de ser parte de una campaña antinacionalista comunista (Loayza 2016). Es en este

1 Esta investigación fue financiada por la Universidad Nacional Mayor de San Marcos - RR Nº5753-R-21 con código de proyecto E21150151.

2 El ensayo ha tenido varias reediciones desde entonces, la última se encuentra en Contreras y Glave (2015) donde se reúne una selección de textos que resumen, en parte, el debate sobre la independencia del Perú en el siglo XX. En ese mismo texto se encuentra una selección de El azar en la historia...

(C) Los autores. Este artículo es publicado por ISHRA, Revista del Instituto Seminario de Historia Rural Andina de la Facultad de Ciencias Sociales de la Universidad Nacional Mayor de San Marcos. Este es un artículo de acceso abierto, distribuido bajo los términos de la licencia Creative Commons Atribución 4.0 Internacional (CC BY 4.0) [https://creativecommons.org/licenses/by/4.0/deed.es] que permite el uso, distribución y reproducción en cualquier medio, siempre que la obra original sea debidamente citada de su fuente original. 
contexto en que se publicó El azar en la historia... De hecho, Basadre en este debate tomó una posición de centro al indicar que su objetivo no era sumarse a la "historiografía patriótica oficial" ni al "revisionismo absoluto"; lo suyo sería más bien un "revisionismo analítico" (p. 12). Pero la forma en cómo se organiza el libro y en las fuentes teóricas en que se apoya, es evidente que sus argumentos se dirigen a criticar casi punto por punto los artículos de La Independencia en el Perú y en particular al ensayo de Bonilla y Spalding.

La primera parte del libro se entiende como una crítica a la nueva perspectiva historiográfica que Bonilla y Spalding representan: la nueva historia social. Influida por la escuela francesa de los Annales y el marxismo, esta perspectiva analiza el pasado prestando atención a los aspectos económicos y sociales de la sociedad bajo conceptos tomados de las ciencias sociales como el de estructura y clases sociales, por ejemplo. Para 1972 esta perspectiva era novedosa dado que la academia de historiadores de entonces — muy bien representada por la CNSIP — más bien se interesaba en la historia política y, en términos generales, consideraba que la objetividad se basaba en la descripción del documento. La historia, además, tenía un fin pedagógico: fortalecer la "nacionalidad". Decir que Basadre se enmarca en esta perspectiva no es del todo correcta, si bien se especializó en la historia política, siempre - como veremos más adelante - estuvo atento y dialogante con otras perspectivas historiográficas, aunque ello no fuese evidente por su estilo de narración ${ }^{3}$.

Los cuestionamientos de Basadre se dirigían a los excesos del estructuralismo económico y social que pretendía explicar toda la realidad social y que cuyo mejor ejemplo, al parecer, era precisamente el ensayo de Bonilla y Spalding. Basadre, para su crítica, se apoya en fuentes teóricas distintas a las de la historia social: la teoría de juegos, la probabilidad, el azar y el estructuralismo — no la francesa, sino la del biólogo Gunter S. Stent-. Así, argumenta que en la historia un hecho no lleva necesariamente a otro sino a una serie de probables hechos igualmente posibles y donde el azar juega también un rol en el acontecer histórico. Estas variables se ubican dentro de una serie de acontecimientos, es decir, dentro de un proceso histórico. Estas ideas teóricas sirven a Basadre para reflexionar sobre el proceso de independencia del Perú en el apéndice del libro, la parte central y más extensa del libro, titulada precisamente: "La serie de probabilidades dentro de la Emancipación peruana".

En el apéndice Basadre responde las ideas de la compilación de Bonilla a quien, por cierto, incomprensiblemente no menciona, incluso cuando realiza una cita textual de parte del ensayo escrito con Spalding - hecho que esta segunda edición no se corrige o comenta con una nota a pie de página - ${ }^{4}$. Basadre apunta sus críticas al texto de Chaunu y en menor medida a los de Vilar y Halperin, aunque también a la historiografía nacionalista, pero de forma indirecta, cuestionando algunas tesis de José de la Riva Agüero5. Ubica la independencia dentro del contexto mundial y se apoya en diversos estudios europeos y norteamericanos de historia política para tal fin. Al igual que en la primera parte, sus fuentes bibliográficas son distintas a la de la historia social: la historia política y cultural estadounidense (Darnton, Palmer, Raeff), inglesa (Laslett, Stone) y francesa (Godechot, Furet, Richet). De esta última, aunque algunos historiadores eran cercanos o parte de la escuela de los Annales, estaban ya revisando las interpretaciones estructuralistas de la revolución francesa. Basadre mostraba así que estaba al tanto de los debates sobre la revolución inglesa, francesa y rusa y citaba libros que la historiografía peruana "descubrió" veinte años después y que hoy todavía son referentes en la historiografía política. Las fuentes primarias 3 Para una reflexión más amplia ver Espinoza Claudio (2003).

4 La cita de Basadre se encuentra en la página 125. Esta corresponde a la página 51 del ensayo de Bonilla y Spalding (1972).

5 En su "Historia de la idea de patria" (1954) Basadre había ya presentado el tema de las "probabilidades" respecto a la independencia, así como su crítica a Chaunu. 
utilizadas eran conocidas por los especialistas: prensa, folletos, relatos de viajeros, entre otros. Todos ellos impresos. La novedad estaba en el uso de algunos volúmenes de la colección documental de la independencia del Perú que por entonces estaba publicando la CNSIP.

El apéndice está dividido en tres partes y Basadre sigue un estilo de narración erudita y un tanto ensayística, sobre todo en las dos últimas partes donde el tema del azar y las probabilidades son el trasfondo - no siempre evidente — de la argumentación. En la primera parte, "La erosión en el Imperio hispánico de ultramar: el caso del Perú", reflexiona sobre el impacto de la Ilustración, la Revolución francesa y las reformas borbónicas en el virreinato peruano y su relación con la independencia. Cuestiona tanto las ideas que le asignan una influencia directa, como aquellas que las consideran como poco relevantes. Así, por ejemplo, las reformas borbónicas no tuvieron el alcance que buscaron y ya para inicios del siglo XIX no quedaba mucho de ellas. La Ilustración y la Revolución francesa no pasaron desapercibidas en el Perú, a pesar de que influyeron en una minoría fueron importantes para formar cierta identidad política, aunque no directamente independentista.

En la segunda parte, "El retardo en la Independencia peruana", Basadre afirma que si bien hay hechos que dan forma a una identidad autonomista en el Perú y América — que son mencionados en la primera parte- estos por sí solos no hubieran "madurado" sin la acción de otros imprevistos factores externos que llevaron finalmente a la crisis de la monarquía hispana (la invasión de Napoleón, la guerra en la península y América, etc.). Es decir, esta no se explica solo por causas estructurales o por la existencia de una conciencia nacional. Por lo demás esos hechos dieron lugar a muchas "probabilidades históricas". Respecto a las rebeliones populares, Basadre parte de cuestionar que su explicación priorice aspectos económicos. Siguiendo algunas ideas de Furet sobre las "clases inferiores" en la Europa moderna, resalta que las rebeliones tienen diferentes causas y objetivos que están lejos de buscar desaparecer la estructura desigual de clases; unas pueden responder a situaciones de crisis económica, otras a la defensa de privilegios. Por lo demás, estas se vuelven más complejas a nivel local donde el descontento general se puede articular con conflictos de diferente tipo e involucrar actores no necesariamente populares. Basadre extrapola estas reflexiones para las conspiraciones y rebeliones en el Perú de inicios del siglo XIX. Ello es entendible en tanto se carecía por entonces de estudios históricos sobre movimientos sociales alejados de la narración política y patriótica. La historiografía social posterior siguió la línea de reflexiones planteadas por Basadre, vía Furet/Annales ${ }^{6}$.

La rebelión del Cusco de 1814, de otra parte, es presentada por Basadre como la más importante por su amplitud y objetivo político, pero que careció de un conjunto de "probabilidades objetivas" para tener éxito (apoyo de Lima, una eficiente organización militar, apoyo local consistente, etc.). La fortaleza militar realista y la debilidad criolla retardó la independencia. No obstante, el descontento y el ánimo patriota se mantuvo en un sector criollo pese a las atrocidades de la violencia de los rebeldes indígenas. Así, por ejemplo, el asesinato de la familia de José Rufino Echenique - futuro presidente del Perú-, no le impidió unirse al bando patriota cuando llegó San Martín. Para Basadre ese caso concreto cuestiona la tesis del "miedo a la rebelión social" de los criollos frente a los indígenas propuesto por Bonilla y Spalding.

La tercera y última parte, "Luces y sombras en la Independencia peruana", responde las tesis de Bonilla y Spalding sobre la independencia peruana "concedida", el "silencio popular" y sobre el legado de la independencia en la república. Sobre las dos primeras tesis Basadre presenta evidencias y casos que demuestran el descontento local, planes de conspiración y la participación de diferentes sectores de la sociedad apoyando a San Martín y a Bolívar en la guerra. Aquí Basadre 6 Para un repaso y reflexión más amplía de esos estudios ver Escanilla Huerta (2021). 
resalta que los actores nacionales no eran figuras pasivas, sino que imponían sus deseos como el hecho defender el modelo político republicano, por ejemplo. A diferencia de la "historiografía ciegamente nacionalista", Basadre no sostiene que todo el pueblo andino fue hostil a los realistas y más bien muestra casos como el del pueblo realista de Huanta que complejizan la dinámica del conflicto político.

Si en gran parte del apéndice Basadre contradice las tesis de Bonilla y Spalding, ya en la última parte muestra más bien coincidencias — salvo con el tema del imperialismo inglés del que mantiene dudas - Así, cuando Basadre compara la Revolución francesa con la independencia peruana para establecer sus diferencias afirma que está no se generó por un movimiento social interno con demandas anti-señoriales y anti-fiscales y que impulsó un movimiento campesino. En tal sentido, tras su consumación tampoco hubo cambios económicos y sociales revolucionarios, no obstante, surgió un Estado independiente. Aunque un "Estado empírico" y con "abismo social" pendiente de resolver. El cierre del libro recuerda la de su otro texto clásico, Perú: problema y posibilidad (1931), afirmando que, pese a los problemas de la independencia, hay una promesa para el país de "ser".

El azar en la historia... es un libro que entre el sesquicentenario y el bicentenario de la independencia peruana no ha perdido interés debido a su amplitud de miras en su análisis de los hechos históricos. Asimismo, pese a la gran cantidad de libros y artículos sobre la independencia, en la actual coyuntura no hay debates. No al menos las que pueden interesar a un público amplio. En tal sentido, la polémica en que se inserta el libro resulta no solo interesante, sino que además anima al público en general a plantearse preguntas sobre nuestro pasado.

\section{Referencias}

Basadre Grohmann, J. (2021). El azar en la historia y sus límites. Con un apéndice: la serie de probabilidades dentro de la emancipación peruana. Lima: Taurus.

Basadre Grohmann, J. (1954). Historia de la idea de Patria en la Emancipación del Perú. Mercurio Peruano, (330), 645-683.

Bonilla, H., Spalding, K. (1972). La independencia en el Perú: las palabras y los hechos. En Heraclio Bonilla, et. al, La independencia en el Perú (pp. 15-64). Lima: Instituto de Estudios Peruanos.

Contreras, C. y Glave, L. M. (2015). La independencia del Perú: ¿concedida, conseguida, concebida? Lima: Instituto de Estudios Peruanos.

Escanilla Huerta, S. (2021). El rol de los sectores indígenas en la independencia del Perú. Bases para una nueva interpretación. Revista de Indias, 81(281), 51-81.

Espinoza Claudio, C. (2003). Jorge Basadre, la historiografía y la política. Examen de un proyecto de construcción de una nueva historiografía nacional. Investigaciones sociales, (11), 249-289.

Loayza Pérez, A. (2016). Del Perú mestizo a la “idea crítica”. Historiografía, nación e Independencia, 1920-1980. En Alex Loayza Pérez (Ed.). La independencia peruana como representación. Conmemoración, historiografía y escultura pública (pp. 25-80). Lima: Instituto de Estudios Peruanos.

\section{Alex Loayza Pérez}

https://orcid.org/0000-0002-9413-643X

aloayzap@unmsm.edu.pe

Universidad Nacional Mayor de San Marcos

Publicado online: 27/12/2021 